of his master's easy chair. A short time ago I had occasion to call on Mr. W., and the dog was, as usual, occupying the chair, from which he was removed to his basket. He showed his resentment of this disturbance of his slumbers by becoming very restless. Presently he trotted over to the door, which he rattled by pushing with his nose, his usual method of attracting attention when he wished to go out. His master immediately rose and opened the door, but instead of the dog going out he rushed back and jumped into the chair his master had just vacated! The rapid wagging of his tail and the expression on his face showed the dog to be very pleased with the result of his ruse. The dog has repeated the same joke once or twice since, with much evident delight to himself.

ARTHUR J. HAWKES.

Bournemouth.

\section{Occurrence of a Tropical Form of Stick-Insect in} Devonshire.

A FBW weeks ago I obtained through the kindness of a lady in Paignton a living specimen of a stick-insect, one of several individuals which had appeared in her garden. My example was met with on the plaster outside a window, and owing to the tenacity with which it adhered to its position required some force to dislodge it. I preserved it in captivity for about a fortnight, at the close of which period it died, having refused to feed on the foliage of any of the plants with which it was supplied.

It is an apterous female, and is, I think, referable to Cladoxerus phyllinus, Gray. I have not been able to obtain any clue as to the cause of its occurrence. Robert O. Cunningham.

\section{A Probable Variable of the Algol Type.}

ON the evening of October 29, while examining the Pleiades with a binocular at about 9 p.m., G.M.T., I noticed that the star Atlas (27 Tauri) was slightly fainter than Pleione (28 Tauri), a little to the north of it. I did no remember at the time what the relative brightness of the stars was, and on looking them up in the Harvard Catalogues I was surprised to find that Atlas was measured 3.80 magnitude, and Pleione 5. 19 . I find that all the estimates for the last 300 years agree in making Atlas considerably brighter than Pleione. The nights following October 29 were cloudy, but on the evening of November 9 I found Atlas of its usual brilliancy, and more than I magnitude brighter than Pleione. The observed variation was therefore about $I \frac{1}{2}$ magnitude. As Atlas is not a long period variable, it seems probable that it is a variable of the Algol type. The star should be watched, and observations for variable radial velocity would be very desirable.

J. E. GORE.

\section{THE PREVIOUS EXAMINATION AT CAMBRIDGE.}

THE first report of the studies and examinations syndicate, issued on November II, deals with the previous examination. This is the first public test imposed on candidates for degrees at the university, and since 1822 has included a compulsory examination in both Latin and Greek. In response to a demand for reform sent up by teachers, parents, professional men, and men of science in the direction of making Greek, at least for some students, an optional subject-a demand supported by a large majority of head-masters and assistant masters in the secondary schools-the syndicate proposes a new scheme for the examination in which this demand is recognised.

Briefly, the scheme provides that for all candidates the "previous" shall consist of three parts, to be taken together or separately at the convenience of the student. Part i. includes Latin, Greek, French, and German, the papers in each to require unprepared translation and composition. "Set books" are abolished. A candidate may take Latin and Greek, or either Latin or Greek together with French or German. In other words, he must take two languages, of which one at least is an ancient classical language. Part ii. includes arithmetic, algebra, and geometry as heretofore. The paper on "Paley's Evidences" is abolished; it is not a school subject, and it is got up largely by an effort of memory from a bare abstract or analysis. Part iii. includes English composition as a compulsory subject, and two of the following alternatives: (I) English history; (2) scripture knowledge (a Gospel and Acts in English); (3) elementary organic chemistry; (4) experimental mechanics and other parts of elementary physics. Natural science, in the shape of physics and chemistry, is thus introduced for the first time. The syndicate was urged by weighty authorities to require from all candidates some knowledge of science; but, after full consideration, it is unable to recommend more than the inclusion of science among the alternative subjects. Probably, in view of the imperfect organisation of science teaching in many public schools of the classical type, to make science compulsory at this stage would have involved the adoption of a standard so low as in effect to discredit the subject.

For the benefit of certain students, among whom students of science may certainly be reckoned, to whom the power to read French and German is more important than a special knowledge of one only of these, it is provided that the translation papers in each of the two languages may be substituted for the translation and composition papers in one alone.

For a boy from a modern school or technical institute, therefore, the examination provided might thus include, for example, Latin, French, and German translation, mathematics, English composition, elementary chemistry, and elementary physics. On the other hand, a boy from a purely classical school might take the following combination: Latin and Greek mathematics, English composition, scripture, and English history. For him the examination would be an improvement on the old " previous" examination, not only by reason of the higher standard proposed to be required, but also on account of the wider range of literary subjects to be included.

The report represents a serious attempt to recognise and to provide for the changes which are in progress in modern English education. By asking from every aspirant evidence that he has seriously studied one, at least, of the classical languages, it safeguards the traditional virtue ascribed to that form of intellectual training. By admitting that modern languages (including English) and physical science are possible components of a liberal education in the twentieth century, it indicates a certain widening of academic aims and ideals that may lead to better things hereafter. There is little doubt that the report will meet with strenuous opposition from those who, in the supposed interest of ancient learning, dare not make any concession to modern knowledge. It will not escape criticism from reformers of the more advanced type, who would sweep away Latin as well as Greek. But the proposals at least remedy a genuine grievance in a practical manner, and they make for progress along the lines of a sounder and broader education than the older universities have yet sought to foster.

\section{THE EXPLORATION OF THE TRANSVAAL. ${ }^{1}$}

$\mathrm{I}$ this first report, drawn up by $\mathrm{Mr}$. H. Kynaston and his colleagues, we see the prospect of healthy rivalry between the geologists of Cape Colony and of the newly acquired territories to the north. No time has been lost in issuing one of those small folio

I "Geological Survey of the Transvaal. Report for the Year 1903." Pp. ii $+4^{8}$; with 24 plates, folding maps, and sections. (Pretoria: Printed at the Government Printing Office, 1904.)

$$
\text { No. } 1829 \text {, vOL. 7I] }
$$

